\title{
ENHANCEMENT IN BIOGAS PRODUCTION FROM PRESS MUD
}

\author{
Srinivas Kasulla \\ Biogas Expert \\ Hyderabad, Telangana, India
}

\author{
S J Malik \\ Waste to Energy Expert \\ Pune, Maharashtra, India
}

\begin{abstract}
Biogas age from the anaerobic processing has uncovered to be probably the best innovation as another fuel source to petroleum derivatives, which can decrease the unfavorable ecological contamination and yield supplement muck as bio manure. Biogas production from sugarcane press mud has enormous potential for energy age. Nonetheless, to empower the enhancement of the anaerobic digestion (AD) measure substrate trademark ought to be painstakingly assessed. In this paper the biogas improvement has been talked about and completed. Tests of press mud from different locales from the nation were investigated as far as aggregate and unstable solids, macronutrients, minor components and dietary benefit. Biochemical methane potential was performed to assess the energy capability of the press mud as per various sorts of sugarcane plants. Methane yields changed extensively, for the most part because of the various areas, water quality, soil structure and manures utilized for developing the sugar stick just as sugar and additionally ethanol creation measures.
\end{abstract}

Keywords - Anaerobic Digestion, Press Mud, Biogas, Methane, Micronutrient

\section{INTRODUCTION}

In spite of the fact that the joined production of sugar and ethanol dependent on sugarcane is perceived as one of the most proficient frameworks for biofuels creation (yield per hectare), Indian Sugarcane industry is answerable for the age of various sorts of natural waste which, much of the time, are still not being appropriately treated, particularly from the energy perspective.

The vast majority of the sugar businesses and the ranchers in India use press mud as the natural manure in mix with spent wash or legitimately without spent wash on the sugar fields for supplement reusing without past vivacious use, the other aspect of the deposits of the sugar business are generally utilized as fuel in low-productivity cogeneration frameworks (i.e., bagasse). Non-controlled assimilation of such waste on the fields may prompt the arrival of a lot of methane, which may upset the constructive outcome of bioenergy usage on the environmental change relief. The anaerobic digestion (AD) of press mud can be viewed as a promising system, since the digestate could at present be utilized to somewhat supplant the mineral manures on the sugarcane fields and the delivered biogas could be moved up to BioCNG and sold as another energy item by the sugarcane businesses just as the new biogas innovation providing organizations

Below table gives a picture of Sugar Cane, Area and Production in the past till present in India:

Table 1

\begin{tabular}{|c|c|c|c|}
\hline Sugar Cane & $\begin{array}{c}\text { Area } \\
\text { (Mha) }\end{array}$ & $\begin{array}{c}\text { Yield } \\
\text { (MT/ha) }\end{array}$ & $\begin{array}{l}\text { Product } \\
\text { (MMT) }\end{array}$ \\
\hline 1990-1991 & 3.69 & 65.39 & 241.05 \\
\hline 1995-1996 & 4.15 & 68.02 & 282.09 \\
\hline $2000-2001$ & 4.32 & 69.35 & 299.32 \\
\hline 2001-2002 & 4.41 & 67.09 & 295.95 \\
\hline $2002-2003$ & 4.52 & 63.58 & 287.38 \\
\hline 2003-2004 & 3.94 & 59.39 & 233.86 \\
\hline 2004-2005 & 3.66 & 64.74 & 237.08 \\
\hline $2005-2006$ & 4.2 & 66.93 & 281.17 \\
\hline $2006-2007$ & 5.15 & 69.03 & 355.52 \\
\hline $2007-2008$ & 5.06 & 68.81 & 348.18 \\
\hline 2008-2009 & 4.44 & 64.19 & 285.02 \\
\hline $2009-2010$ & 4.18 & 70.01 & 292.3 \\
\hline $2010-2011$ & 4.89 & 70.09 & 342.38 \\
\hline $2011-2012$ & 5.08 & 71.07 & 361.03 \\
\hline $2012-2013$ & 5.06 & 67.38 & 341.2 \\
\hline $2013-2014$ & 5.01 & 70.26 & 352.14 \\
\hline $2014-2015$ & 5.14 & 70.44 & 362.33 \\
\hline $2015-2016$ & 4.96 & 70.25 & 348.45 \\
\hline $2016-2017$ & 4.38 & 70.02 & 306.7 \\
\hline $2017-2018$ & 4.95 & 79.800 & 395 \\
\hline $2018-2019$ & 5.2 & 79.81 & 415 \\
\hline
\end{tabular}




\section{International Journal of Engineering Applied Sciences and Technology, 2020 \\ Vol. 5, Issue 5, ISSN No. 2455-2143, Pages 213-216 \\ Published Online September 2020 in IJEAST (http://www.ijeast.com)}

Before being actualized for an enormous scope, the biogas cycle ought to be deliberately assessed, particularly with respect to the substrate's qualities, as natural issue and dietary benefit, macronutrients, minor components, and explicit biogas creation. Those boundaries legitimately impact some other significant cycle boundaries, for example, the $\mathrm{pH}$, aggregation of inhibitors, potential macronutrients, and minor components lacks, too debasement rates.

\section{NUTRIENT BALANCE:}

A few creators recommended that for an appropriate $\mathrm{AD}$ measure a parity among the fundamental supplements: carbon, nitrogen, phosphorous and sulfur is vital. On the off chance that a specific substrate or model the press mud if has a too high $\mathrm{C}: \mathrm{N}$ proportion, or in another words, has nitrogen insufficiency, it might adversely impact the microbial network working. That implies an immediate effect on the capacity to deliver compounds that are expected to the carbon usage, causing a fragmented transformation of the carbon contained in the press mud, bringing about lower methane yields. Then again, press mud that contain significant levels of nitrogen can make hindrance the $\mathrm{AD}$ cycle by means of aggregation of poisonous smelling salts $\left(\mathrm{NH}_{3}\right)$ created from protein debasement or by urea change and this was exceptionally seen in the spent wash treated press mud whenever utilized for producing biogas.

Phosphorus and sulfur are additionally viewed as basic supplements for the AD cycle. While sulfur is a significant constituent of amino acids, phosphorus is required for microbial development during the arrangement of energy transporters ATP (adenosine triphosphate) and NADP (nicotinamine adenine dinocleotide phosphate), a significant constituent of nucleic acids, just as it assumes a significant part in the support of an ideal $\mathrm{pH}$. In any case, when sulfur is found in high focuses, sulfates are diminished to sulfide by the supposed sulfatelessening microorganisms, prompting two potential hindrances. On one hand, because of thermodynamic preferences sulfatediminishing microbes outcompetes methanogens for hydrogen and acetic acid derivation and then again, hydrogen sulfide $\left(\mathrm{H}_{2} \mathrm{~S}\right)$, a result of sulfate decrease, toxically affects different gatherings of microscopic organisms. Notwithstanding that, when found in high fixations, $\mathrm{H}_{2} \mathrm{~S}$ can make consumption some biogas plant parts, for example, the joined warmth and force units (CHP), biogas updating frameworks, and metal lines and tanks, prompting significant expenses of support. The significance of minor components during AD is moderately notable, particularly for significant compounds and cofactors engaged with various strides of the cycle, where extraordinary metal particles are required. A few creators revealed higher gas yields, enhancements for measure dependability and arriving at higher natural stacking rates (OLR) through the supplementation of cobalt, copper, iron, molybdenum, nickel, selenium, tungsten, and zinc. While creature squander model cows excrement and so on are relied upon to require less alterations, $\mathrm{AD}$ of press mud faces minor component inadequacies. Hence, it is normal that the substrate arrangement assumes a significant part for the minor component prerequisites during the $\mathrm{AD}$ cycle, being a significant boundary to be considered during the improvement of stable cycle with novel substrates. Extra perspectives additionally should be considered, particularly with respect to the minor components' accessibility for microbial take-up, fundamentally determined by metal speciation, $\mathrm{pH}$ and cycle temperature, applied natural stacking rate, just as the substance cycles of precipitation and complexation. Moreover, another viewpoint that ought to be considered when a biogas idea dependent on press mud is a work in progress, is the irregularity of the sugar stick and the possibility of limiting the negative impacts by saving and putting away aspect of the press mud and dodging the unpredictable issue misfortunes during the capacity of the press mud in the slow time of year. In this way, permitting a higher usage of the biogas framework during the whole year.

\section{MACRONUTRIENTS AND TRACE ElEMENTS:}

To give direction during the planning of an $\mathrm{AD}$ framework dependent on sugarcane squander, we played out a broad assessment of press mud with various creation frameworks by getting press mud from different areas the nation over.

Characteristics and Physiochemical analysis of Press Mud:

Table 2

\begin{tabular}{|c|c|c|c|}
\hline \multirow{2}{*}{ Parameters } & \multirow{2}{*}{ Units } & \multicolumn{2}{|c|}{ PRESS MUD* } \\
\cline { 3 - 4 } & $\begin{array}{c}\text { Average } \\
\text { Value }\end{array}$ & $\begin{array}{c}\text { Standard } \\
\text { Deviation }\end{array}$ \\
\hline $\mathrm{TS}$ & $\begin{array}{c}\text { \% Fresh } \\
\text { matter }\end{array}$ & 28.00 & \pm 4.00 \\
\hline $\mathrm{VS}$ & $\% \mathrm{TS}$ & 75.00 & \pm 11.05 \\
\hline $\mathrm{C}$ & $\% \mathrm{TS}$ & 43.00 & \pm 7.50 \\
\hline $\mathrm{N}$ & $\% \mathrm{TS}$ & 1.80 & \pm 0.30 \\
\hline $\mathrm{P}$ & $\% \mathrm{TS}$ & 0.67 & \pm 0.23 \\
\hline $\mathrm{S}$ & $\% \mathrm{TS}$ & 0.21 & \pm 0.04 \\
\hline $\mathrm{Ca}$ & $\mathrm{mg} / \mathrm{l}$ & 4500.00 & \pm 2100 \\
\hline $\mathrm{Na}$ & $\mathrm{mg} / \mathrm{l}$ & 7.20 & \pm 7.50 \\
\hline $\mathrm{K}$ & $\mathrm{mg} / \mathrm{l}$ & 820.00 & \pm 340 \\
\hline $\mathrm{Mg}$ & $\mathrm{mg} / \mathrm{l}$ & 910.00 & \pm 240 \\
\hline
\end{tabular}

*Press mud samples were brought from 6 different sugar industries from all across the country and each sample were tested 3 times for variations

By and large it was discovered that the qualities were discovered lower than the suggested qualities for the biogas cycle and now and again, it could prompt outrageous, to handle hindrance if the excess nitrogen is changed over into alkali. A portion of the examples of press mud introduced a normal C:N proportion thought about legitimate for $\mathrm{AD}$ (24:1). In not many cases sulfur content was seen and it was assessed that if the sulfur content is left without diminishing high sulfur substance 


\section{International Journal of Engineering Applied Sciences and Technology, 2020 \\ Vol. 5, Issue 5, ISSN No. 2455-2143, Pages 213-216 \\ Published Online September 2020 in IJEAST (http://www.ijeast.com)}

can cause a few unfortunate impacts as the opposition of sulfate-decrease with methanogenesis, lessening the change of natural acids into biogas, other than likewise adversely affecting the bioavailability of minor components inside the digesters, though now and again the sulfur content was practically $25 \%$ then it was seen in different examples. Perceptions exhibited that the expansion of phosphate and sulfate expanded impressively the debasement rate and biogas creation supporting the function of $\mathrm{P}$ and $\mathrm{S}$ as restricting full scale supplements for certain AD frameworks. The improvement of a co-absorption technique to adjust the macronutrients of the sugarcane squander clearly could bode well from the monetary perspective, when it could somewhat supplant the expansion of significant expense synthetic substances as, urea that normally would be utilized to adjust the $\mathrm{C}: \mathrm{N}$ proportion during the biogas cycle.

An absence of some significant minor components was seen from the creation of press mud from various locales and it fluctuated radically and still numerous reasons of these varieties couldn't be found. From the examples of the press mud piece, less minor components were seen beneath the proposal esteems for instance, tungsten and selenium whereas the molybdenum was discovered to be the least of the cutoff. This happens, presumably, in light of the fact that at the modern stage where press mud is created, metal-based coagulants and flocculants are included during the physical-synthetic cycle that eliminates contaminations from sugarcane juice.

Trace Element Content in Press Mud Samples brought for experiments:

Table 3

\begin{tabular}{|c|c|c|c|}
\hline \multirow{2}{*}{ Parameters } & \multirow{2}{*}{ Units } & \multicolumn{2}{|c|}{ PRESS MUD } \\
\cline { 3 - 4 } & & $\begin{array}{c}\text { Average } \\
\text { Values }\end{array}$ & $\begin{array}{c}\text { Standard } \\
\text { Deviation }\end{array}$ \\
\hline $\mathrm{Fe}$ & $\mathrm{mg} / \mathrm{kg}$ & 28400.00 & \pm 23800 \\
\hline $\mathrm{Ni}$ & $\mathrm{mg} / \mathrm{kg}$ & 14.80 & \pm 6.20 \\
\hline $\mathrm{Co}$ & $\mathrm{mg} / \mathrm{kg}$ & 3.55 & \pm 1.70 \\
\hline $\mathrm{Mo}$ & $\mathrm{mg} / \mathrm{kg}$ & 1.22 & \pm 0.85 \\
\hline $\mathrm{W}$ & $\mathrm{mg} / \mathrm{kg}$ & 0.30 & \pm 0.60 \\
\hline $\mathrm{Mn}$ & $\mathrm{mg} / \mathrm{kg}$ & 600.00 & \pm 220 \\
\hline $\mathrm{Cu}$ & $\mathrm{mg} / \mathrm{kg}$ & 44.80 & \pm 5.50 \\
\hline $\mathrm{Se}$ & $\mathrm{mg} / \mathrm{kg}$ & 0.01 & \pm 0.01 \\
\hline $\mathrm{Zn}$ & $\mathrm{mg} / \mathrm{kg}$ & 120.00 & \pm 22 \\
\hline
\end{tabular}

The methane yield accomplished by the six examples of press mud didn't present any significant distinction regarding last methane yield, shifting between 430 - 460 1/kg natural dry issue. At the point when the outcomes are changed over to methane creation per ton of accessible press mud in the sugar enterprises will be around $82-90 \mathrm{M} 3$ of crude biogas. Once more, it will rely further upon the all out solids of the accessible press mud as in two cases it was seen that we could get crude biogas creation of practically around $100-105$ M3 for every ton of press mud.

Every day biogas creation from press mud was noted down for various maintenance times. At first all the digesters with various examples were examined later in the second stage the digesters were seen by expansion of the minor components. The digester with just press mud and the digester where the iron was included begun indicating biogas age from the fifth day. While it was seen that the digesters when nickel and cobalt were included, it began indicating biogas age from the first day itself. Creation of biogas expands continuously and shows most extreme yield around following 18 days in all the examples which were taken for absorption. It was discovered that when iron was added to the press mud in a different digester it indicated a pinnacle estimation of biogas on the eighteenth day. Comparative outcomes were seen when nickel and cobalt were included yet at different levels.

The most elevated creation of biogas of Cobalt was seen on 22nd day, Nickel shows its pinnacle yield on 25th day. The anaerobic assimilation measure reached out around 35 days. The biogas creation began declining after 28th day onwards in 4 examples though in 2 examples it began diminishing simply after 32nd day. It was seen in the entirety of our tests that the expansion of Iron shows a most extreme yield in the anaerobic processing of press mud. In this way, minor components assume a huge part in the pace of anaerobic absorption of the press mud. Aggregate biogas creation can be corresponding to the particular development pace of methanogens in the anaerobic digester just as the innovation choice accomplished for the anaerobic assimilation of press mud. It was discovered that CSTR is the best appropriate innovation to create biogas from the press mud. Iron expansion to squeeze mud demonstrated practically $30 \%$ a greater number of gas than the press mud alone. After seventeenth day onwards the biogas creation began indicating its consequences for age designs in all the six examples and the digester with just press mud demonstrated the less measure of biogas from all the examples tried. In light of the above examinations it very well may be handily said that expansion of the minor components to the biogas plant chipping away at press mud improves the gas creation from $20-30 \%$ relying upon the controlled anaerobic processing conditions.

\section{CONCLUSION}

Anaerobic absorption of press mud is old idea. Everybody is currently sure of creating biogas from press mud or in blend of blending press mud to other feed stocks, for example, chicken litter, bovine fertilizer and so forth, However upgrading the biogas creation from the equivalent biogas plants dealing with the press mud is a key factor when one glances at the plausibility perspective in the bigger biogas plants. Expansion of minor components has end up being probably the best answer for upgrade the biogas. It was discovered that very nearly 20$30 \%$ of biogas improvement was seen when one adds minor components to the biogas digesters. Once more, contingent 


\section{International Journal of Engineering Applied Sciences and Technology, 2020 \\ Vol. 5, Issue 5, ISSN No. 2455-2143, Pages 213-216 \\ Published Online September 2020 in IJEAST (http://www.ijeast.com)}

upon the volume of the digester one needs to plan and include appropriately. Care ought to be taken while including the minor components as over portion the minor components to the digester is additionally not recommendable.

\section{REFERENCE}

1. Malik SJ, Gunjal BB and Kasulla Srinivas (July 2018). Study of Upgradation Technologies to treat biogas from spent wash to BioCNG at $64^{\text {th }}$ DSTA Annual Convention, Gandhinagar

2. Malik SJ, Gunjal BB, Kasulla Srinivas and Gunjal Aparna (April 2019). Spentwash and Pressmud to BioCNG - An Overview at Bioenergy from Sugar Industry - A way forward for sustainability, Nijalingappa Sugar Institute, Belagavi

3. Rouf MA, Bajpai Pramod and Jotshi Chand (2010). Optimization of Biogas generation from Pressmud in batch reactor at Bangladesh journal of scientific research 45 (4) (pp. 371-376)

4. Sundaranayagi S, Sirajunnisa A and Ramasamy V (2017). Production of biogas by anaerobic digestion of Pressmud using iron, cobalt and nickel at Indian journal of science and research 14 (1) (pp. 374-377)

5. Rouf MA, Islam MS, Bajpai PK and Jotshi CK (2013). Techno-economic assessment of biogas production from Pressmud in Bangladesh at Bangladesh journal of scientific research 48 (1) (pp. 51-58)

6. Agrawal KM, Barve BR and Khan SS. Biogas production from Pressmud at second international conference of emerging trend in engineering, IOSR journal of Mechanical $\&$ Civil engineering (pp. 37-41)

7. Schmidt Thomas, Nelles Michael, Scholwin and Proter Jurgen (Sep 2014). Trace element supplementation in the biogas production from wheat stillage - Optimization of metal dosing at Bioresource Technology Vol 168 (pp. 80-85)

8. Gustavsson, J, Shakeri Yekta, S., Sundberg, C, Karlsson, A, Ejlertsson, J, Skyllberg, U and Svensson, BH (2013). Bioavailability of cobalt and nickel during anaerobic digestion of sulphur-rich stillage for biogas formation at Applied Energy, Elsevier Vol 112 C (pp. 473-477)

9. Irvan Matseh (Oct 2012). The effect of Ni and Co as trace metals on digestion performance and biogas produced from fermentation of palm oil effluent at International journal of waste resource Vol 2(2) (pp. 16-19)

10. Irvan Matseh (2012). The effect of FE concentration on the quality and quantity of biogas produced from fermentation of palm oil effluent at International journal of science and engineering Vol 3(2) (pp. 35-38)

11. Raju NR, Devi SS and Nand K (1991). Influence of trace element on biogas production from mango processing waste in $1.5 \mathrm{~m} 3 \mathrm{KVIC}$ digester at Biotechnology letters Vol 13 (pp.461-464)

12. Bajpai Pramod and Jotshi Chand (2010). Optimization of Biogas generation from Pressmud in batch reactor at Bangladesh journal of scientific research 45 (4) (pp. 371376)

13.Janke, L, Leite A, Batista, K.; Weinrich S, Strauber H, Nikolausz M, Nelles, M.; Stinner, W (Aug 2016). Optimization of hydrolysis and volatile fatty acids production from sugarcane filter cake: Effects of urea supplementation and sodium hydroxide pre-treatment at Bioresource technology Vol 199 (pp. 235-244)

14. Wang Y, Wang J Zhang and Meng L (2009). Effect of volatile fatty acids concentrations on methane yield and methanogenic bacteria at Biomass and Bioenergy Vol 33 (5) (pp. 848-853) 